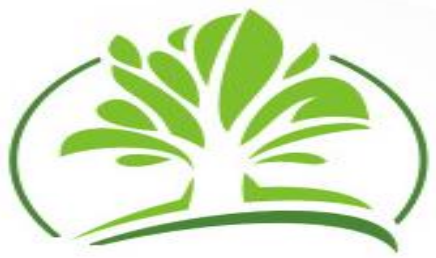

\title{
JJEOSHS
}

Jumuga Journal of Education, Oral Studies, and Human Sciences (JJEOSHS)

www.jumugajournal.org submission@jumugajournal.org

\section{Volume 1, Issue 1, December 2018}

\section{Vision 2030 and the Gender Question in Kenya}

\author{
By Catherine Wambui Njagi, PhD
}

\section{Abstract}

The article sets out to demonstrate the question of gender violence as a critical concern as Kenya seeks to implement her ambitious vision 2030. In other words, how can gender based violence affect the Implementation of Kenya vision 2030? Can it hinder Kenya's ambitious enterprises in the $21^{\text {st }}$ century? Certainly, Kenya's Vision 2030 is a long term development blue print that seeks to transform Kenya into a newly industrializing middle income country. In so doing, it aims at providing a high quality life to all its citizens in a clean and secure environment. The plan is anchored on three pillars, economic, social and political governance. The economic pillar aims to achieve an economic growth rate of $10 \%$ per annum; and sustaining the same till 2030 in order to generate more resources that will eventually address Kenya's development goals. In turn, the social pillar seeks to create just, cohesive and equitable social development in a clean and secure environment; and the political pillar seeks to realize an issue based, people centered, result oriented and accountable democratic system. In view of this, Gender Based Violence is an umbrella term for any harmful act that is perpetrated against a person's will and which is based on socially ascribed (gender) differences between men and women. Gender-based Violence (GBV) describes the specific type of violence that is linked to the gendered identity of being a woman or man. Gender based Violence traumatizes men, women and children. It destroys careers, and hurts the national economies among other negative effects. The main objective of this article is to show the link between Gender Based Violence and Kenya vision 2030. Methodologically, it starts by summarizing the vision 2030 highlighting its major strategies like education and training, health sector, Equity and poverty reduction, environment management, tourism, water and sanitation, electoral and political processes, democracy and public service, gender and youth among others and major flagship 
projects like Konza Techno city, expansion of port of Mombasa, the building of standard gauge railway, modernization of Jomo Kenyatta airport, expansion of Lamu port among others. Using the society of International development report and other organizations who have constantly audited the implementation of the vision 2030 since it began in 2008, the article will show how gender based violence will slow the achievement of the vision 2030. It will also show how reducing gender based violence would help in its achievement. The materials in this article have been methodologically gathered through participant observation, reading of relevant literature, field research conducted in 2015 and sampling the city of Nairobi which largely speaks for Kenya and the larger East Africa

Key words: Kenya's Vision 2030, Gender Based Violence, Poverty eradication, the Gender Question

\section{Introduction}

Kenya Vision 2030 is a long term development blue print that seeks to transform Kenya into a newly industrializing middle income country providing a high quality of life to all its citizens in a clean and secure environment. According to the National Economic and Social Council (NESC) Report of 2007, page 1, the plan is anchored on three pillars, economic, social and political governance $^{1}$. The NESC report further explains that the economic pillar aims to achieve an economic growth rate of $10 \%$ per annum and sustaining the same till 2030 in order to generate more resources to address development goals. According to NESC, the social pillar seeks to create just, cohesive and equitable social development in a clean and secure environment and the political pillar aims to realize an issue based, people centered, result oriented and accountable democratic system. These aims cannot be efficiently achieved in an insecure social economic environment epitomized by Gender Based Violence.

\footnotetext{
${ }^{1}$ Government of Kenya, Kenya vision 2030: A global competitive and prosperous Kenya, Ministry of planning and National Development and National Economic and Social Council Report(Nairobi: 2007)page 1
} 
According to the government of Kenya report on Economic Recovery Strategy for Wealth and Employment Creation of 2003 page 1, with the change of government that occurred in Kenya in 2002, there was an intense focus on the part of policy makers to address the dismal economic growth the country had experienced for nearly two decades and this response was captured initially in the Government's Economic Recovery Strategy for Wealth and Employment Creation generally referred to as ERS, which was the immediate short-term approach to the malaise besetting the economy. As the new government settled in, it soon became apparent that short-term strategies had to be put in the context of long-term development planning. It was with this in mind that the Government created the National and Economic Social Council (NESC) as an advisory group to the government on the articulation of a long-term vision of the economy and more broadly the future direction of the Nation. NESC's core mandate was the production of a long-term vision for the country Encapsulated in Kenya Vision 2030, a globally competitive and prosperous Kenya. According to the NESC report of 2007 page 2, this long-term vision has become the reference point for all government policy activities and if it is achieved, Kenya will become a middle income country with stable economic, political and social growth.

A number of organizations have audited the vision 2030 trying to find out whether it will be achieved. One of these institutions, Society for International Development (SIDA), in their 2010 report, page 1, found that although vision 2030 can be achieved, it was surrounded by many challenges but one of the greatest challenges is gender based violence ${ }^{2}$. This article will discuss on the impact of Gender based Violence in the achievement of Kenya vision 2030. It will define Gender based Violence and summarize Kenya vision 2030. It will then show how gender based violence will hinder the achievement of Kenya vision 2030 and finally show how reducing Gender Based Violence will increase the chances of achieving the Kenya vision 2030.

\section{Gender Based Violence}

The United Nations defines Gender Based Violence as an umbrella term for any harmful act that is perpetrated against a person's will and that is based on socially ascribed (gender) differences between men and women ${ }^{3}$. Gender-based Violence (GBV) describes the specific type of violence

\footnotetext{
${ }^{2}$ Society for International development Audit Report on the impact of kenya vision 2010, page 1

${ }^{3}$ World health organization report on Intimate partner and sexual violence against Women, 2014 page 1
} 
that is linked to the gendered identity of being a woman or man. Acknowledging that the most common victim of GBV is the female gender, the World Health Organization report of 2014 page 1 observes that for women in many parts of the world, violence is a leading cause of injury and disability, as well as a risk factor for other physical, mental, sexual and reproductive health problems. GBV takes form in a variety of behavior including physical, mental, or social abuse and sexual abuse and harm ${ }^{4}$.

According to World Health Organization report of 2014, page 2, the United Nations General Assembly presented a partial list of GBV which included: Physical, sexual and psychological violence within the family, Child sexual abuse, Dowry-related violence, Marital rape, Female genital mutilation, Rape and sexual abuse, Sexual harassment in the workplace and educational institutions, trafficking in women, Forced prostitution. A significant characteristic of GBV is that the victim has no choice to refuse or pursue other options without severe social, physical, or psychological consequences owing to the fact that it is rooted in a society's social structure, that is, the society's nerve Centre or its system of norms, values and beliefs. It is also an important characteristic that GBV can be perpetrated by an intimate partner as well as a stranger, and within and outside the family and home environment.

World Health Organization report of 2014, page 4 portrays Gender-based violence as a leading cause of girls and women's death and incapacity globally. In addition to facing physical and psychological trauma and injury, Girls and women who suffer violence are at a higher risk of contracting sexually transmitted infections including HIV and AIDS. They may also face unintended pregnancies, adverse pregnancy outcomes and chronic health problems. Survivors of GBV often suffer rejection and further victimization from partners, family and community members due to the shame and stigma associated with such violations.

\section{Kenya Vision 2030}

The National Economic and Social Council report of 2007, page 1 defines Kenya Vision 2030 as the country's development blueprint covering the period 2008 to 2030. It aims at making Kenya a newly industrializing, "middle income country providing high quality life for all its citizens by the

\footnotetext{
${ }^{4}$ World health organization report on Intimate partner and sexual violence against women, 2014 page 2
} 
Jumuga Journal of Education, Oral Studies, and Human Sciences (JJEOSHS)

year $2030^{5}$. The Vision has been developed through an all-inclusive stakeholder consultative process, involving Kenyans from all parts of the country and is based on three "pillars" namely; the economic pillar, the social pillar and the political pillar (Ibid). Kenya vision 2030 program plan was established after the successful implementation of the Economic Recovery Strategy for Wealth and Employment Creation (ERS) which saw the country's economy back on the path to rapid growth since 2002, when GDP grew at $0.6 \%$ rising to $6.1 \%$ in 2006 (Ibid).

The economic pillar aims at providing prosperity of all Kenyans through an economic development program aimed at achieving an average Gross Domestic Product (GDP) growth rate of $10 \%$ per annum. The social pillar seeks to build "a just and cohesive society with social equity in a clean and secure environment". The political pillar aims at realizing a democratic political system founded on issue-based politics that respects the rule of law, and protects the rights and freedoms of every individual in the Kenyan society (Ibid). The Kenya Vision 2030 is to be implemented in successive five-year Medium Term plans with the first such plan covering the period 2008 - 2012. And then another five-year plan will be produced covering the period 2012 to 2017, and so on till 2030.6

\section{Major Strategies:}

\section{Health Sector}

Vision 2030 aims at provision of the efficient integrated and high quality and affordable health care hoping to become the regional provider of the highly specialized healthcare. This will be done through devolution of funds and management of the healthcare to the communities and the district medical officers leaving the ministry to deal with policy and research issues and shifting the bias of the national health bill from curative to preventive care. The improved health care for all will come through providing access to those excluded from health care for financial or other reasons. The government aims to carter for people living with HIV/AIDS through supply of free ARVs and

\footnotetext{
${ }^{55} \mathrm{GOK}$, Global competitive, page 1

${ }^{6}$ Government of Kenya, first medium term plan, 2008-2012, Nairobi, Office of the prime minister and Miistry of state and national Development(Government press: 2008)page 1
} 
Jumuga Journal of Education, Oral Studies, and Human Sciences (JJEOSHS)

voluntary counseling. The government aims at partnering with the private sector in improving the quality of the health services delivery to the highest standards. ${ }^{7}$

\section{Education Sector}

Kenya aims at providing globally competitive and quality education training and research. This will be achieved through education act which empowers the minister of education to promote education in Kenya and the progressive development of the institution devoted to the promotion of the education and to secure the effective cooperation, under his general direction or control of all public bodies concerned with education in carrying out the National policy for education. The government aims at developing policies for polytechnics and vocational training centers which aim to mainstream youth polytechnics into a national education and training framework and reposition them to take a leading role in the development of youth for employment and life long learning in the tertiary education sector. The government also aims at establishing systems to ensure the recognition, validation and accreditation of informal learning for youth among other proposals in the education sector ${ }^{8}$

\section{Fairness and Poverty Reduction}

Kenya vision 2030 aims at reducing the number of people living in absolute poverty to the smallest possible proportion of the total population. Kenya aims at a society that guarantees equality of opportunity in accessing public services and providing income generating activities as widely as possible which can be achieved by placing the citizens at a level of income sufficient to carter for basic requirement of healthy and productive life. The correction measures will be introduced to extend such opportunities to regions and communities where they do not exist presently. ${ }^{9}$

\section{Youth Gender and Susceptible Groups}

Kenya vision 2030 strives to ensure equity in power and resource distribution between genders, improved livelihood for all the vulnerable groups and responsible globally competitive and prosperous youth. Kenya aims to capitalize on her international reputation as an athletic

\footnotetext{
${ }^{7}$ GOK, Global competitive, page 104

${ }^{8}$ GOK, Global competitive, page 95

${ }^{9}$ GOK, Global competitive, page 14
} 
Jumuga Journal of Education, Oral Studies, and Human Sciences (JJEOSHS)

superpower by opening up the country for top global sport events encouraged by corporate sponsorship. Kenya plans to increase opportunities all round among women, youth and all disadvantaged groups by increasing their participation in all economic, social and political decision making processes. ${ }^{10}$

\section{Housing and Urbanization}

Going by the current demographic trends, Kenya will be a predominately urban country by 2030 . Vision 2030 will need to plan for decent and high quality urban livelihood for her population. Vision 2030 aims to see decently housed nation in a sustainable environment. This will require annual production of housing units and an initiative for high quality urban planning for regional and urban development planning starting with adequate housing for those living in slums and for the rest of the population. ${ }^{11}$

\section{Major Flagship Projects}

These include but not limited to the building of Konza Techno city, expansion of port of Mombasa, the building of standard gauge railway, modernization of Jomo Kenyatta airport, expansion of Lamu port ${ }^{12}$

\section{How Gender Based Violence Will Hinder the Achievement of Kenya Vision 2030}

According to Gituro Wainaina, the acting director general of Kenya vision 2030, Kenya's ambition of becoming a middle-income economy with per capita income of between $\$ 1,045$ and $\$ 12,736$ hangs in the balance as the government struggles to meet key growth targets under its long-term development plan, Vision 2030. In an article published by Nation media in 2017, Gituro argues using the Latest data from the Kenya Vision 2030 Delivery Secretariat which paints a grave picture of the achievements made in the past eight years with concerns over low levels of economic growth, domestic savings, national investments and employment figures. Kenya's economy has grown at an average rate of four per cent in eight years against a planned 10 per cent and this is

\footnotetext{
${ }^{10}$ GOK, Global competitive, page 133

${ }^{11}$ GOK, Global Competitive, page 143

${ }^{12}$ GOK, Global Competitive, page 86
} 
Jumuga Journal of Education, Oral Studies, and Human Sciences (JJEOSHS)

due to the poor performance of key economic sectors such as agriculture, manufacturing and tourism.

According to the Kenya Vision 2030 Delivery Secretariat, challenges related to lack of funding, lengthy procurement processes and litigation on tender awards, land acquisition and compensation issues as well as high transaction costs have worked out to stifle implementation of flagship projects. However, according to the National Crime Research Centre report (2016) Gender Based Violence is one of the major challenges to the achievement of vision 2030.

As National Crime Research Centre (2016) report notes, Gender based Violence is one of the greatest challenges towards the achievement of Kenya vision 2030. It is viewed as one of the key developmental challenges facing the country. Considering that the Vision for the gender, youth and vulnerable groups sector is that 'men and women enjoy a high quality of life and equal opportunities' we will look at how GBV hinders the achievement of Kenya vision 2030 from different dimensions.

\section{Economic Dimension}

According to the National Crime Research Centre report (2016) Gender based Violence represents a hidden obstacle to economic and social development and hence affecting the achievement of Kenya vision 2030 negatively. By sapping women's energy, undermining their confidence and compromising their health, gender Based violence deprives society of women's full participation. ${ }^{13}$ As Alice Mwajuma has observed, "Women cannot lend their labor or creative ideas fully if they are burdened with the physical and psychological scars of abuse" (Ibid). If Kenya vision 2030 is to become a reality, all Kenyans must contribute towards it and alleviate GBV which contradicts the goals of development (Ibid).

According to the United Nations population report of 2003 and the World Health organization report of 2014, GBV undermines development and hence vision 2030 outcomes because it depletes resources and has various direct and indirect economic and social costs. These include direct costs such as medical, criminal justice, social services as well as non-monetary costs such as increased homicide, suicide, alcohol/drug abuse, depressive disorders. For example, in the

\footnotetext{
${ }^{13}$ Alice Abok Mwajuma, Winds of Hope,(Nairobi: Starman publishers,2004)page 5,7.
} 
Jumuga Journal of Education, Oral Studies, and Human Sciences (JJEOSHS)

United States, the health related costs of rape, physical assault; stalking and homicide by intimate partners are more than $\$ 5.8$ billion every single year (Ibid) World health organization Report (2014) identified larger economic consequences of GBV such as loss of productivity, decreased investment and social impacts such as inter-generational transmission of violence, reduced quality of life, reduced participation in democratic processes. Violence and the threat of violence have been found to significantly reduce women's and girl's opportunities for work, their mobility and their participation in education, training, community activities and wider social networks.

\section{Health Dimension}

According to NESC report of 2007 page 104, the actualization of Kenya vision 2030 is dependent on the physical, mental, social and spiritual health of the Kenyan citizens. The more health citizens are, the greater the chances of achieving Kenya vision 2030. GBV take various forms. First there are physical and reproductive consequences such as, injury, diseases, gastrointestinal problems, infections, gynecological disorders, unwanted pregnancy, menstruation disorders, pregnancy complications, sexual disorders, unsafe abortion and miscarriage among others. There are also emotional and psychological effects including post-traumatic stress disorders, mental illness, suicidal thoughts and behaviors, shame, insecurity, self-hate and self-blame (Ibid).

According to World Health organization report of 2014, the impact of gender-based violence resonates in all areas of health and social programming: survivors of GBV experience increased rates of morbidity and mortality, and violence has been shown to exacerbate HIV transmission, among other health conditions. ${ }^{14}$ Regarding the issue of female genital mutilation/cutting, the consequences include stress, fear, extreme shock, heavy bleeding and sometimes death (Ibid).

\section{Social Dimension}

According to NCRC report of 2016, GBV has adverse effects on the person's functioning which ultimately affects the community, country and the world at large and hence the achievement of Kenya vision 2030. GBV leads to social consequences including social stigmatization, social 'rejection and isolation, loss of roles/functions in society, the blaming of the victim, feminization

\footnotetext{
${ }^{14}$ Isabela Apawo Phiri, Beverly Haddad, African women HIV/AIDS and Faith Communities (Pietermaritzburg: Cluster Publications,2003), page 149
} 
of poverty and increased gender inequality (Ibid). All these consequences have led to an increase in maternal morbidity and has negative effect on the attainment of vision 2030. GBV has an impact on young girls in social, family and school settings. It is an important cause of poor performance and dropout in schools, colleges and Universities. My Study on the impact of violence experiences on retention and achievement found that violence against women, in the form of sexual intimidation, verbal abuse and physical assault was a significant contributor to irregular attendance and underachievement of women. ${ }^{15}$

According to the United Nations Population Fund report of 2008, GBV kills and disables more women aged 15-44 years than does cancer, malaria or even traffic accident. Physical abuse may lead to pregnancy complications like miscarriage, placental abruption, premature delivery, low birth weight and fatal or infant death (Ibid). NCRC report of 2016 agrees that the consequences of sexual abuse on reproductive health includes sexually transmitted diseases and infections including HIV/AIDS, unwanted pregnancy, unsafe abortion, pelvic inflammatory disease, infertility and genital injuries including obstetric fistula. The report shows that when a woman is not able to seek proper health care in the period surrounding pregnancy or after physical abuse, the consequences can be fatal (Ibid).

According to NCRC report of 2016, these outcomes are evident in Kenya where women who suffered during the post-election violence are still enduring similar symptoms. Children who were affected by the post-election violence were also found to suffer from some form of anxiety compared with children who grew in peaceful environment (Ibid). The report further adds that GBV undermines livelihood strategies and economic alternatives and this impoverishes the family.

\section{Political Dimension}

According to Kenya Health demographic survey report of 2014, violence cost the Kenyan Nation the equivalent of $7.3 \%$ of GNP based on costs incurred in the health sector and the justice system as well as lost investment and material loss. Taking into account the death toll of victims, the report estimated a substantial loss of potential production which represents significant economic costs.

\footnotetext{
${ }^{15}$ Catherine w Njagi, Role of Faith based organizations in curbing GBV in Nairobi county Kenya, Unpublished PhD thesis 2017
} 
Jumuga Journal of Education, Oral Studies, and Human Sciences (JJEOSHS)

Continuous usage of such a big amount of resources on issues of GBV will affect the attainment of Kenya vision 2030.

According to the NCRC report of 2016, GBV is felt in all sectors. It burdens the health and security systems diverting funds from the National budget allocation to primary health and education. In terms of macro-level economic production, GBV erodes human capital and accounts for a loss of productivity from both paid and unpaid work as well as foregone value of life time's earning on the part of women who have died. The report shows that GBV further undermines and destabilizes democracy building, good governance and promotion and defense of human rights. It shows that at institutional level, it destabilizes the state, reducing citizens' confidence in government authorities and institutions. It renders it more difficult for government to build a truly democratic and legitimate state and accomplish one of the main duties that is protecting the life and development of citizens and curtailing the implementation of Kenya vision 2030.

Alice Mwajuma agree that development is clearly under threat when women are excluded from participating in, contributing to and benefiting from development initiatives and from political decision making at micro and macro levels since their participation is crucial to promote lasting change $^{16}$. According to the United Nations report of 2006, GBV undermines the eradication of extreme poverty and hunger, achievement of universal primary education, promotion of gender equality and empowerment of women, reduction of child mortality rates, improvement of maternal health, combating HIV and AIDS, ensuring environmental sustainability and developing global partnerships for development all of which require the active participation of all members of the society (Ibid).

\section{Increasing the Chances of Achieving Kenya Vision 2030 by Combating Gender Based Violence}

Both National Crime Research Centre report of 2016 and National Economic and Social Council report of 2007 agree that gender Based Violence will curtail the implementation of Kenya vision 2030. According to SIDA report of 2010, the government should aim at reducing gender inequality in the following ways: -

\footnotetext{
${ }^{16}$ Alice, Winds of hope, page 73
} 
Under the agriculture sector, increase women's access to and control of productive assets (land, capital, inputs) and extension services, and increase their participation in producer organizations. In manufacturing, improve employment terms, especially for women working in the export processing zones, and also increase women's access to finance. In tourism, reduce job segregation (through more specialized training targeted at women), increase women's access to formal finance and create awareness of the rights of women to militate against the negative concerns in the sector. Under the retail trade sector, increase the participation of women in producer groups and ensure that they graduate from small-scale informal activities to more formal and sustainable livelihood options. In financial services, expand access to formal finance and introduce the use of nonconventional collateral for accessing credit, a move that would greatly benefit women whose major constraint to credit access has been lack of collateral. For the business process outsourcing sector, enhance women's skill level (through training) and increase their access to finance to ensure that they are able to take advantage of the opportunities that will arise.

Promoting gender equality is widely acknowledged as an essential component of an effective economic and human development strategy. This has necessitated the integration of gender issues into the design, implementation, monitoring and evaluation of policies and program in the political, economic and societal spheres so that women and men benefit equally. According to World Bank report of 2001, gender equality is a core development issue - a development objective in its own right. It strengthens countries' abilities to grow, reduce poverty and govern effectively.

SIDA report 2010 notes that where gender inequality exists, it is generally women who are excluded or disadvantaged in relation to decision making and access to economic and social resources. Therefore, a critical aspect of promoting gender equality is the empowerment of women, with a focus on identifying and redressing power imbalances and giving women more autonomy to manage their own lives. Gender equality does not mean that men and women become the same, only that access to opportunities and life chances is neither dependent on, nor constrained by, their sex. Advancement of women brings important economic, business and societal impacts on the growth of nations. Internationally, considerable progress has been made in closing the health 
outcomes and education gender gaps. ${ }^{17}$ Despite the gains, the gap between women and men in economic participation (captured through the participation gap, the remuneration gap and the advancement gap) and political empowerment remains wide: only 62 per cent of the economic outcomes gap and only 16 per cent of the political outcomes gap has been closed (Ibid). The Government of Kenya officially acknowledges the importance of gender equality in development. At the national level, the case for gender equality has been strengthened over the years by international and national policy discourse, research and advocacy. Of the three pillars of Vision 2030 economic, social and political gender equality is shown as an important factor in the attainment of the vision 2030. Gender equality is no longer viewed as a separate question, but becomes a concern for all policies and programs.

According to NCRC report of 2016, reducing gender based Violence in Kenya will increase the chances of attaining Kenya vision 2030. The report gives two types of interventions that are needed to combat GBV. The primary intervention which seeks to prevent GBV occurrence by targeting social norms or through educational outreach. These programs focus on societal and situational factors. Secondary intervention is used to address GBV once it has occurred. It includes barterer intervention program, couples' therapy, programs to increase help seeking behavior by targets, civil protective orders, criminal sanctions (Ibid).

Fulata Moyo in her two articles, Building a positive gendered community and what it takes to be a man recognizes that the exaggeration of gender roles by youth and adolescents increases the risk of dating violence and therefore should inform the design of primary interventions in schools ${ }^{18}$. These could be a school based intervention program targeting every adolescent. She argues that other curricula could target adolescent attitudes, specifically those that may justify use of aggression. By changing perceptions of norms of masculinity, the program hopes to encourage more gender equitable behavior and attitude among participants (Ibid). These interventions use social modeling techniques to communicate gender equitable social norms and to transfer relationship skills in peer to peer educational sessions (Ibid).

\footnotetext{
${ }^{17}$ Catherine, Role of FBOs, 2017

${ }^{18}$ Fulata Moyo, What it takes to be a man in Created in God's image from Hegemony to partnership (promoting positive masculinities, Ed. Patricia Sheetattan-Bisnarct and Philip Vinod Peacock (World Communion of reformed Churches: 2010) page 115.
} 
Jumuga Journal of Education, Oral Studies, and Human Sciences (JJEOSHS)

Legal methods can also be used to curb GBV. GBV is a crime and a moral indignation as provided and envisioned in the Kenyan legal system (KLRC, 2010). GBV violates the penal code and is a violation of the constitutional rights of a person. The legal and policy instruments addressing GBV in Kenya are essentially the constitution of Kenya 2010, the Sexual Offences Act 2006, the penal code and the United nations committee on the Elimination of Discrimination against Women (CEDAW). Other relevant instruments include prohibition of FGM/C act 2011 and gender policy 2011 (KLRC, 2010).

Chapter four of the constitution consists of the bill of rights and has the following important provisions in regard to GBV. Section 27(1) indicates that every person is equal before the law and has the right to equal protection and benefit of law. Section 27(2) indicates that equality includes the full and equal enjoyment of all rights and fundamental freedoms. Section 28 indicates that every person has inherent dignity and the right to have that dignity respected and protected. Section 30(1) indicates that a person shall not be held in slavery or servitude and 30(2) indicate that a person shall not be required to perform forced labor.

According to Ndung'u Report of 2011, the Sexual Offence of 2006 is a comprehensive law that criminalizes a wide range of behaviors including rape, sexual assault, defilement, compelled and induced indecent acts with child imbeciles or adults, gang rape, child pornography, child trafficking, sex tourism, child prostitution, exploitation, incest by male or female, sexual harassment, deliberate transmission of HIV and AIDS, stupefying with sexual intent, forced sexual acts for cultural or religious reasons among others. The act also has orders for medical treatment for victims including free HIV phylaxis, emergency pregnancy pill and counseling.

The act provides stiff penalties in which most of the crimes attract minimum of ten years' imprisonment which can be enhanced to life imprisonment (Ibid). Considering the wide range of behavior covered and the stiff penalties, the act is definitely an important tool in combating sexual offences. According to KLRC (2011) the gender policy 2011 seeks to promote interventions for the reduction of sexual and gender based violence and to promote the generation of sex disaggregated data to guide interventions. The foregoing shows the need for vigilance by all stakeholders in enforcement of laws and policies for effective management of GBV. 
Community sensitization targeting men and boys is vitally important in tackling gender-based violence as a way of changing their attitudes and behavior towards women. This should start immediately the child join school because it able to shape his thinking and help him have a sound mind from school. This can be done by teachers in child hood classes especially in schools. It can also be done in churches where Sunday school teachers can be used to teach children about relationships. This especially will have a very positive effect on the boy child as opposed to influencing him negatively. ${ }^{19}$

Text Books and other learning materials should be gender balanced because they play a great role in shaping gender roles. The ministry of education, science and technology should ensure that the books to be used in schools, colleges and universities are gender balanced. For example, they should not use only the male names and use male photographs when they are talking about engineers, professors, pilots etc but should use both male and female to show that both male and female can take any role as long as one is trained for it.

Clear messages for the root causes of GBV should be portrayed for example by use of bill boards in strategic places where community leaders can highlight the vices of gender based violence just like the way HIV and AIDS boards have been displayed. This will help people build some consciousness about gender based violence and know that it is within them so that they can put effort to end it. It can also be put up in public places where people go to rest for everyone to read. In the boards men can be encouraged to take a leadership role in GBV prevention through pictures or writings depicting the effects of GBV in homes and in the society. This will help the boy child to realize that in most cases it is men who are the perpetrators of GBV and therefore will help him want to participate in its fight ${ }^{20}$. These types of campaigns can help reduce GBV to a great extent just like HIV and AIDS campaigns helped reduce HIV and AIDS cases in Kenya. The campaigns will help those who do not recognize that GBV is both sinful and violation of human rights and also a crime. ${ }^{21}$

\footnotetext{
${ }^{19}$ Catherine Njagi, role of FBOs in curbing GBV PhD research 2017

${ }^{20}$ Catherine Njagi, Role of FBOs in curbing GBV PhD research 2017

${ }^{21}$ Catherine Njagi, Role of FBOs in curbing GBV, PhD research 2017
} 


\section{Conclusion}

As we have noted in this article, Kenya's Vision 2030 is envisaged to improve the lives of all Kenyans and offer them a better quality life. If its three main pillars: economic, social and political pillars and their strategies and flagship projects are achieved, Kenya will move to a middle income country with better GNP and enhanced livelihood for all Kenyans. However, there are many challenges facing its achievement and these include funding and other bureaucracies but the greatest challenge is gender based violence. If the vision is to be achieved, Gender based violence must be reduced to the minimum. Clearly, there is no national state that has moved to the higher heights of human progress without addressing the Gender Question. In my view, the secret of Kenya's Vision 2030 is to give the Gender Question a priority in all socio-political discourses rest it becomes another white elephant and/or the shame of Africa. For how can a nation claim to be progressing when irresponsibility across the gender divide becomes the societal norm? how can the match to the dream vision translate to reality when Kenya's parliament fails to embrace the two-thirds gender rule in all socio-political discourses? Are we moving twenty steps forward and 10 steps backward? Clearly the Gender Question drives us to appreciate that a vision is blurred when physical-social-psychological violence against one gender or the other is swept under the curtain and/or reduced to nothing. Addressing the Gender Question is the way to go in Kenya and Africa of the twenty-first century. 
Jumuga Journal of Education, Oral Studies, and Human Sciences (JJEOSHS)

\section{References:}

Njagi, Catherine, "Hope Anchored on Faith Based Organizations: Re-examining Gender Based Violence from a Kenyan Perspective" in the International Journal of Innovative

Research and Knowledge (Volume 2, Issue 5, may 2017) ISSN: 2213-1356

Fitzgerald, LF, Ormarod, OJ, Breaking the silence: The sexual harassment of women in academia and the work place in FL, Denmark and MA paludi(EDS) Handbook of the psychology of Women, Westport, greenwood, 1993)41-50

GOK, Economic Recovery Strategy for Wealth and Employment Creation, Ministry of Planning and National Development (Government press,2003) 1-93

GOK, Kenya Vision 2030: A Global Competitive and Prosperous Kenya, Ministry of Planning and National Delopment and National Economic and Social Council (NESC, Nairobi, 2007) 1162

GOK, First medium term Plan,2008-2012, Nairobi: Office of the prime minister and ministry of state planning, national Development (Government press, 2008) 1-100

Elizabeth Amoah et all, Cultural practices and HIV/AIDS and African Woman's voice (Accra:

SWL press, 2005) 78-98, 103-104,113

IBRD, Gender and economic growth in Kenya, (Washington D.C,,,International bank for

Reconstruction and development/The world bank,2007)

Kassman, Margot, Overcoming violence: Challenge to the churches in all places (Switzerland:

WCC Publications), 19-31

Getui, Mary and Kanyandago, Peter, From Violence to peace, a challenge to African Christianity

(Nairobi: Acton Publishers, 2001)7-36, 164-186

Patricia Sheerattan-Bisnarct and Philip Vinod peacock, Created in God's image from

Hegemony to partnership (A church manual on men as partners) promoting positive masculinities) (world communion of reformed Churches, 2010)115-119

Kanyoro, R.A, Njoroge, J.N, Groaning in Faith: African women in the Household of God, Nairobi: Acton Publishers,1996)204-214

Mombo, Esther, Doing Theology from the Perspective of the Circle of Concerned African Women Theologians in Journal of Anglican studies, Volume 1, Issue 1, London, Sage publication, 2009, 51-56

Oduyoye, M.A, Who Will Roll the Stone Away? The Ecumenical Decades of Churches in 
Jumuga Journal of Education, Oral Studies, and Human Sciences (JJEOSHS)

Solidarity with Women, Geneva: (WCC publications, 1990) 1-10

Rakoczy, Susan, In her name, Women doing Theology. Dorpspruit: Cluster Publications, 2011, 198-254 